\title{
Multi-component friction testing of full-scale drill pipe specimen
}

\author{
V. Tikhonov ${ }^{1}$, M. Giers ${ }^{2}$, V. Yakhimovich ${ }^{2}$, B. Shemyakinsky ${ }^{2}$ \\ \& L. Ring ${ }^{3}$ \\ ${ }^{I}$ Aquatic Co., a Weatherford Company, Moscow, Russia \\ ${ }^{2}$ St. Petersburg State Polytechnic University (SPbSPU), Russia \\ ${ }^{3}$ Weatherford Int., Houston, USA
}

\begin{abstract}
The paper presents the results of testing conducted to determine hoop and axial friction components for drill pipe specimens subjected to complex rotation inside a piece of casing. This experiment was performed in water using the SPbSPU's wear bench which was modified specifically to permit independent rotation of drill pipe section and casing, as well as drill pipe axial sliding. Hoop and axial friction force components were determined during these tests as a function of relative velocity of contact point in complex rotation. The test results were used to establish empirical dependence of these friction force components on axial and relative hoop velocities at transition from sliding to rolling friction. The obtained results have allowed formulations of more precise friction model, which is crucial for the torque and drag analysis of a drillstring inside the wellbore.

Keywords: drillstring, complex rotation and sliding, axial and hoop friction forces, testing, empirical model.
\end{abstract}

\section{Introduction}

An important problem in drilling mechanics which remains challenging is the development of an adequate model of friction force for a drillstring in complex rotation about its center of mass and the wellbore axis while simultaneously sliding along the wellbore axis. Such complex movement of the drill pipe is typical for rotary drilling and tripping operations with rotation in inclined and horizontal wells. 
Drilling practice [1] and theory [2] show that while a drill pipe rotates around its axis, the contact point between a drill pipe and a wellbore is not usually stationery but in a constant oscillating motion relative to the wellbore axis (fig. 1). Oscillation amplitude is small when rotary speed is relatively small. However, when rotary speed is «sufficiently» high and the friction factor value is high but still realistic, drill pipe can start backwhirling inside the wellbore. This complex rotation is similar to a gear engagement, when a pinion rolls within a large gear.

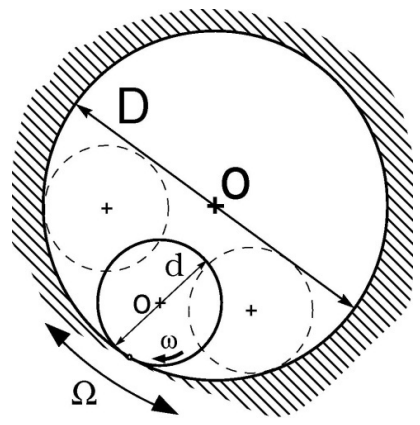

Figure 1: Complex rotation of a drill pipe in a wellbore.

The ideal whirling condition without sliding, just like for the gear engagement, looks like this:

$$
v_{r}=v_{\varphi}-v_{\psi}=0,
$$

where $v_{\varphi}=0.5 \omega d ; v_{\psi}=0.5 \Omega D ; v_{r}=$ velocity of a point on the drill pipe surface relative to the instantaneous velocity center (for the sake of simplicity in what follows we will refer to it as the contact point velocity); $d=$ drill pipe diameter; $D=$ wellbore diameter; $\omega=$ drill pipe angular velocity relative to the center of mass $o ; \Omega=$ drill pipe axis angular velocity relative to the wellbore axis.

The ideal drill pipe whirling involves only rolling friction. But as the difference between the velocity components $v_{\varphi}$ and $v_{\psi}$ increases, sliding friction develops. In real life situations, whirling motion may be happening simultaneously with slipping motion when $v_{r}$ values are small and then, there should be a transition zone where sliding friction will act simultaneously with rolling friction.

Unfortunately, the majority of static and dynamic models of a drillstring do not define this transition from sliding to rolling friction. Such simplification of the model can lead to a significant overestimation of a drill pipe frictional torque losses in rotary drilling.

Another very important aspect of this problem related to the impact that a drill pipe complex rotation has on the longitudinal friction force in drilling and tripping operations involving rotation (fig. 2). 


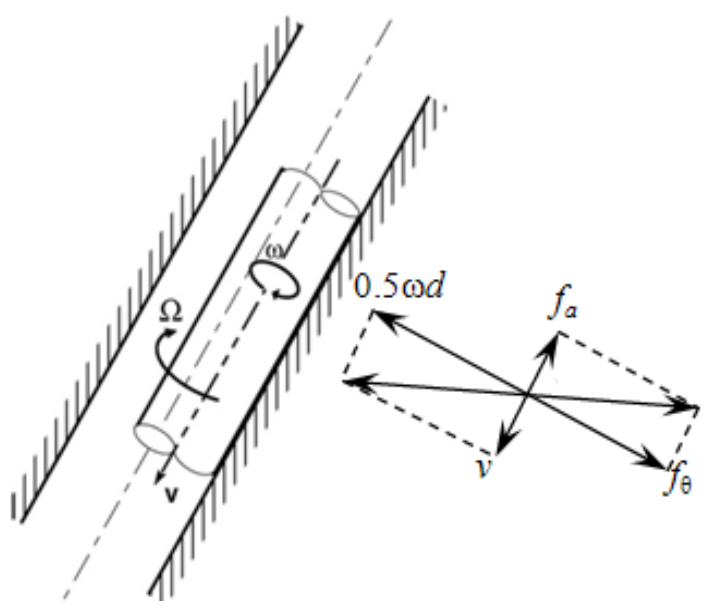

Figure 2: Schematic of friction forces acting on the rotating drill pipe in drilling operations.

The standard approach to determine friction forces in case of a drill pipe longitudinal movement coupled with rotation does not take drill pipe whirling into account. Instead it utilizes Coulomb model of friction, which states the following [3]. The drill pipe resultant velocity vector is equal to the sum of the hoop velocity vector with the absolute value $v_{\varphi}$, and the axial velocity vector $\mathbf{v}$. The friction force acts in the direction opposite to the resultant velocity vector. The hoop $f_{\theta}$ and the axial $f_{a}$ components of this force are proportional to the resultant velocity vector projections for the appropriate directions:

$$
\begin{gathered}
f_{\theta}=k_{\theta 0} v_{\varphi} /\left(v_{\varphi}{ }^{2}+v^{2}\right)^{1 / 2}, \\
f_{a}=k_{a 0} v /\left(v_{\varphi}{ }^{2}+v^{2}\right)^{1 / 2},
\end{gathered}
$$

where $k_{\theta 0}=$ Coulomb sliding friction factor in circumferential direction; $k_{a 0}=$ Coulomb sliding friction factor in axial direction.

Providing that $v_{\varphi}>>v$, which is almost always true in drilling operations, $f_{\theta} \sim$ $k_{\theta 0}, f_{a} \sim k_{a 0} v / v_{\varphi}$. It is obvious that the friction longitudinal component can be lowered considerably by means of increasing a drill pipe angular velocity $\omega$.

However, the following question arises. In case of a drill pipe complex rotation with whirling, what hoop velocity value should be used for determining the longitudinal friction component $f_{a}$ (eqn. (2))? At first sight, it appears that in this case the drill pipe hoop velocity $v_{\varphi}$ should be replaced with the contact point velocity $v_{r}$ (eqn. (1)). But the relative velocity $v_{r}$ can drop to zero under the ideal whirling conditions. Then, as follows from eqn. (3), $f_{a} \sim k_{a 0}$, the effect of the axial friction force decreasing, due to the drill pipe rolling, will disappear. 
Let us state two main problems that have to be resolved in order to understand the effect of rotation on the friction force value:

1) At what ratio of a drill pipe angular velocity relative to the center of mass to the whirling velocity the hoop friction force component should be considered to be the sliding friction force and at what ratio it becomes rolling friction?

2) How does a drill pipe whirling affect axial component of the sliding friction force?

We were not able to find the answers to these questions in prior art so special experiments to determine multi-component friction of drill pipes have been designed.

Following section gives description of the wear bench as well as procedure to prepare specimens for testing and the measurement system. Section 3 contains test results. The last section provides the analysis of the results, conclusions and recommendations on how to use the obtained results to improve friction models for drilling mechanics applications.

\section{Preparation for testing}

The SPbSPU's wear bench (fig. 3) was specially modified for multi-component friction testing. The schematic of the modified testing bench is shown on fig. 4 .

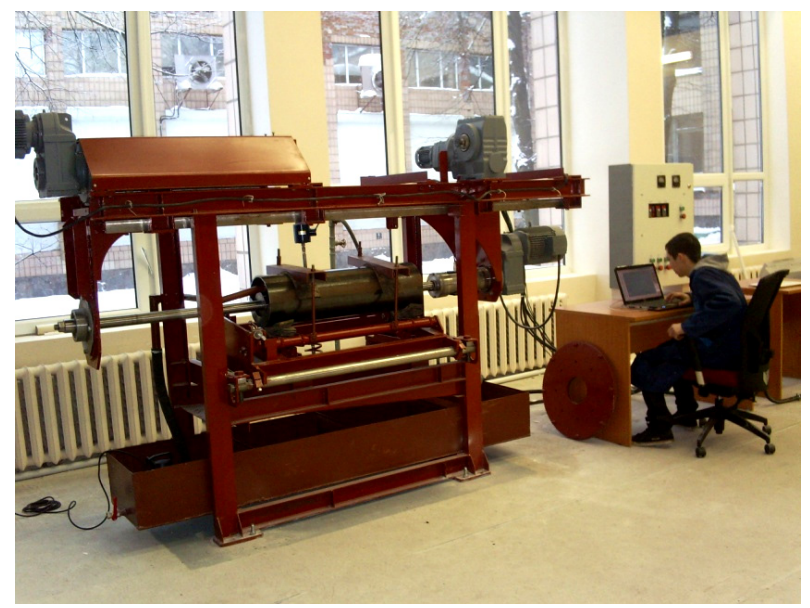

Figure 3: $\quad$ The wear bench general view. 


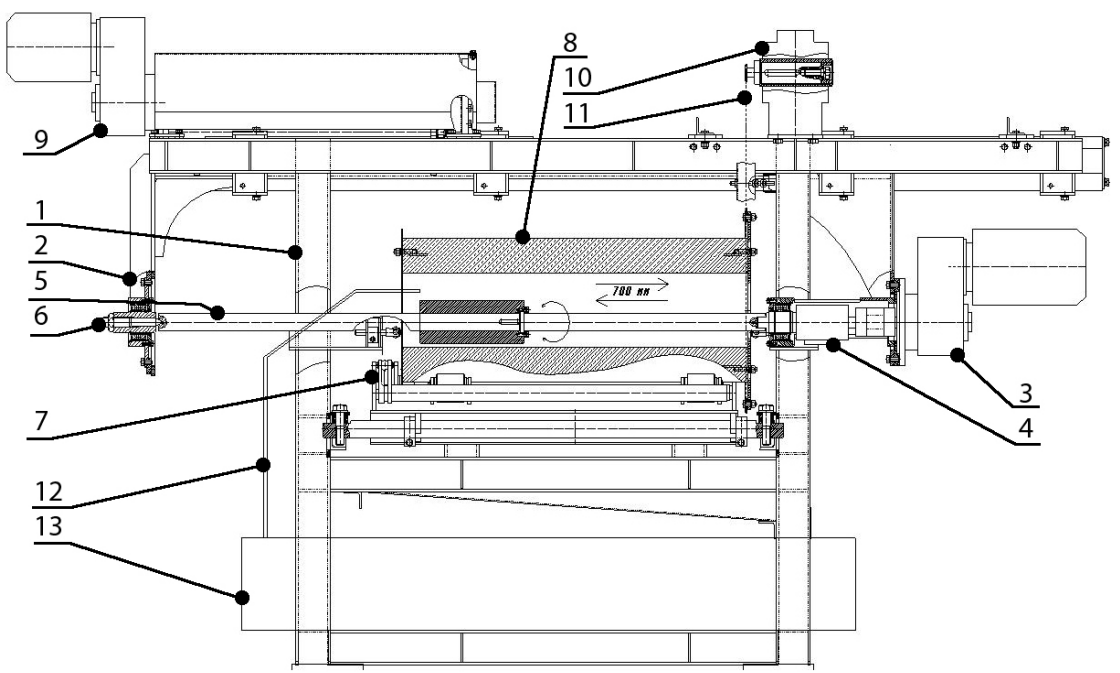

Figure 4: The schematic of the testing bench for the multi-component friction.

The base of the testing bench is a stationary frame 1. The following components are attached to the base frame:

- moving carriage 2 with the specimen rotary actuator 3 and torque gauge 4;

- $\quad$ shaft 5 with the specimen attached to it and the axial force gauge 6;

- floating underframe 7 with casing 8 imitating a borehole and the contact force sensor (not shown in fig. 4);

- specimen axial movement actuator 9;

- actuator 10 that transfers the torque to the casing via the chain gear 11;

- water reservoir 13 and pipeline 12 , which moves the water inside the casing.

The testing bench allows doing the following experiments:

- conduct friction testing of drill pipe specimens 90-203 mm diameter and up to $300 \mathrm{~mm}$ long;

- ensure the drill pipe rotation in both directions up to $150 \mathrm{rpm}$;

- ensure the casing rotation up to $40 \mathrm{rpm}$;

- ensure that the contact force acting on the specimen pressed against the casing is not more than $300 \mathrm{~kg}$;

- ensure specimen's reciprocating longitudinal movement with the velocity not to exceed $5 \mathrm{~m} /$ hour and stroke up to $700 \mathrm{~mm}$;

provide for independent movements of the system elements: specimen and casing rotation and longitudinal movement as well as their combined movement (any combination). 
Continuous measurement and recording of data such as number of rotations, specimen longitudinal force, contact force, axial force and the friction torque. The following gauges were used:

- magneto-type detector MP-981 - to measure rpm;

- sensor to weigh TXM-K500 - to measure the contact force;

- weight measuring strain gauge $\mathrm{C} 2 \mathrm{~A}-0.2-\mathrm{C} 3$ (Russia) - to measure the axial force;

- rotary torque meter TRB-20K - to measure torque.

The specimen was made out of a drill pipe tooljoint, material - steel $40 \mathrm{CrMoV}$ high quality, surface hardness $=320 \mathrm{HB}$, O.D. $=178 \mathrm{~mm}$, length $=$ $100 \mathrm{~mm}$. Casing - steel TN110, surface hardness $=243 \mathrm{HB}, 23 \mathrm{HRC}$, I.D. -220 $\mathrm{mm}$.

Before the start of each test casing and specimen surfaces were machined to roughness $\boldsymbol{R}_{\boldsymbol{a}} 3.2$, then cleaned by washing in running water and finally wiped clean with a rag. Figure 5 shows the outer appearance of the specimen before the start of the testing.

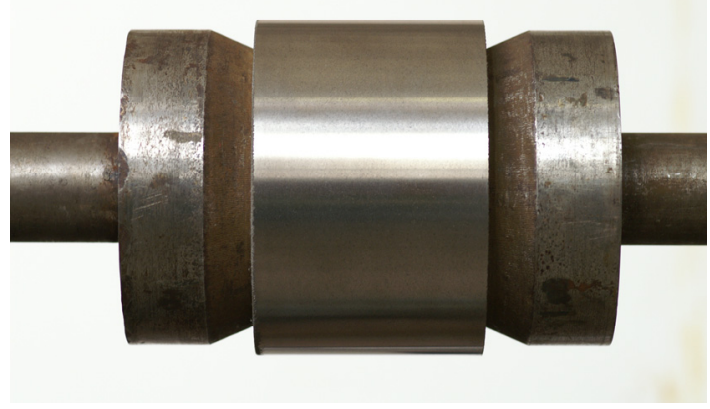

Figure 5: $\quad$ Specimen's outer appearance before the start of the testing.

The testing was conducted in water with water being pumped into the contact zone at the flow rate of 5 liter/min.

\section{Test results}

Before the start of the complex rotation testing the sliding friction coefficients were determined for the hoop and longitudinal directions, $k_{\theta 0}$ and $k_{a 0}$. The testing was performed for three contact force values: 50,100 and $150 \mathrm{~kg}$. The test results are as follows: $k_{\theta 0}=0.171-0.193, k_{a 0}=0.237-0.255$.

\subsection{Testing of a specimen in complex rotation}

During testing the casing rotary speed was kept constant, equal to 37-38 rpm. The specimen's rotary speed was changed by small increments allowable by this type of equipment $\sim 1 \mathrm{rpm}$. The experiment was conducted for three contact force values: 50,100 and $150 \mathrm{~kg}$. 
Figure 6a shows typical change in the specimen hoop friction force component and the hoop velocity in oscillating mode. The recorded data were averaged during post processing. Fig. 6a-c shows averaged change of the specimen hoop friction force component and the hoop velocity data measured in these three tests.

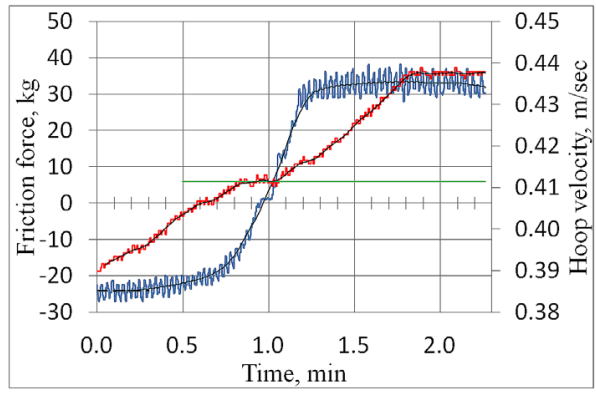

a)

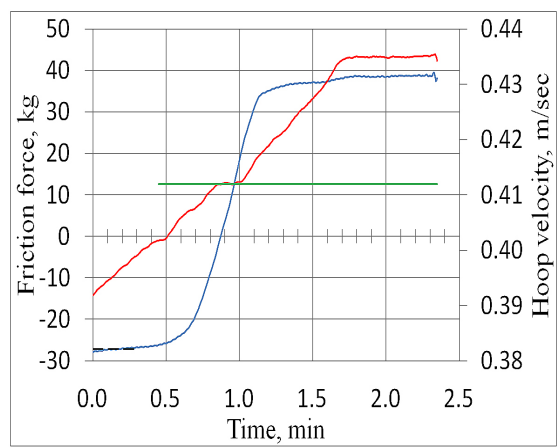

b)

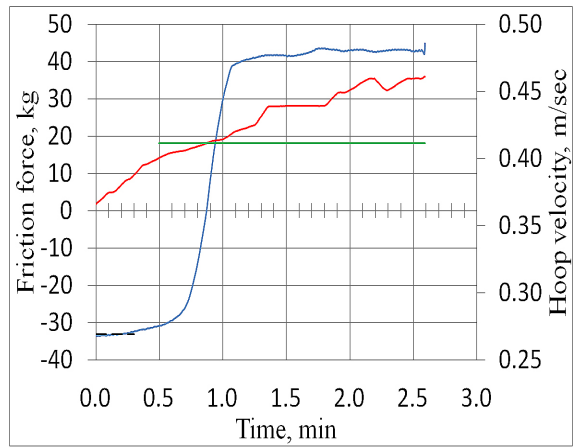

c)

Figure 6: Changes in the specimen hoop friction force component and the velocity over time in complex rotations for different values of the contact force: a) 50, b) 100 , c) $150 \mathrm{~kg}$. (See online for color version of this figure.) velocity.

The dependence of friction factor in hoop direction, that correspond to the measured values of friction force, versus the relative hoop velocity at the contact point $\bar{v}_{r}$, obtained during the three tests, are presented in fig. 7a-c, where

$$
\bar{v}_{r}=\frac{\omega d-\Omega D}{0.5(\omega d+\Omega D)} .
$$




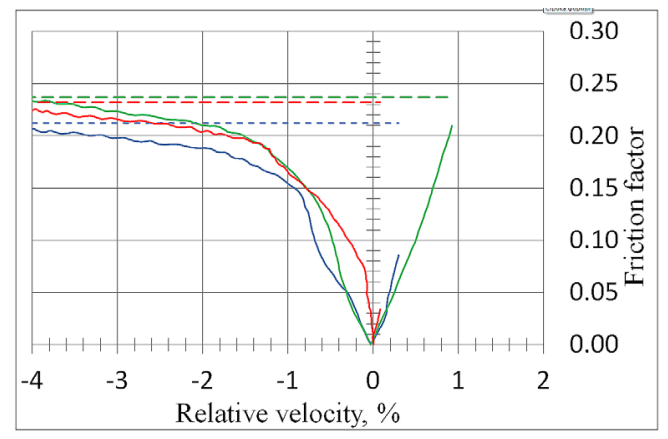

a)

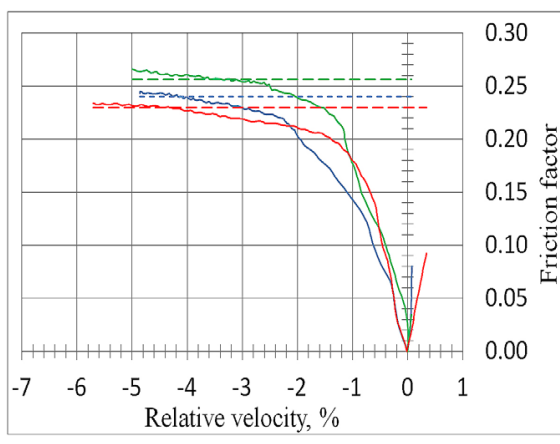

b)

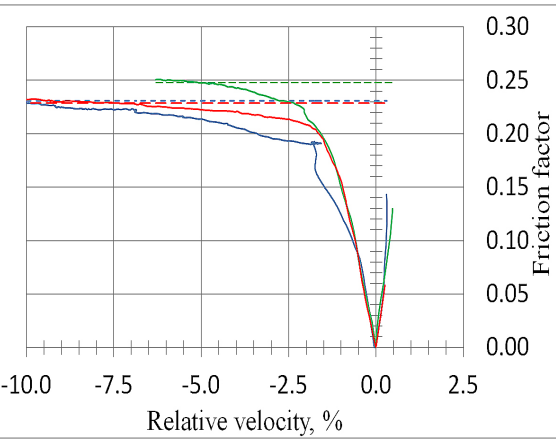

c)

Figure 7: The dependence of the hoop friction factor vs. the relative hoop velocity at the contact point for different values of the contact force: a) 50, b) 100 , c) $150 \mathrm{~kg}$.

As it appears from the curves shown in fig. 7a-c, when the value of the contact hoop velocity is zero, friction force is practically zero. In truth, in case of ideal whirling, $\bar{v}_{r}=0$, as was mentioned above, there is always rolling friction present. However, this force is 2-3 orders of magnitude less than sliding friction force and gauges cannot detect it.

Presented friction factor dependencies are somewhat asymmetrical with respect to the zero relative hoop velocity at the contact point. It is caused by the sign change of the torque applied to a casing when the casing passes through point $\bar{v}_{r}=0$. As a result, the tension in the gear chain strands changes, and in turn the contact force changes as well. Only left part of the friction factor dependence in the circumferential direction $k_{\theta}\left(\bar{v}_{r}\right)$, was taken into account during data processing, which corresponds to $\bar{v}_{r} \leq 0$. The small area of positive relative velocities in these curves is given for information only. 


\subsection{Testing with complex rotations and a longitudinal movement of a specimen}

During testing the casing rotary speed $\Omega=37-38 \mathrm{rpm}$ and the specimen longitudinal velocity $v=0.001 \mathrm{~m} / \mathrm{sec}$ were kept constant. The specimen rotary speed was changed with the increment of $1 \mathrm{rpm}$. The experiment was conducted again for three contact force values: 50,100 and $150 \mathrm{~kg}$.

The records of variables change for each experiment are shown in fig. 8a-c.

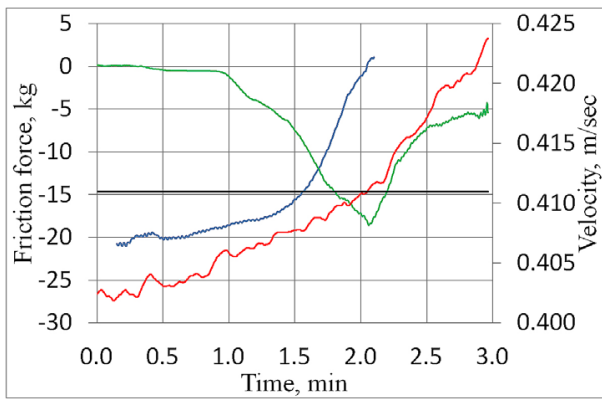

a)

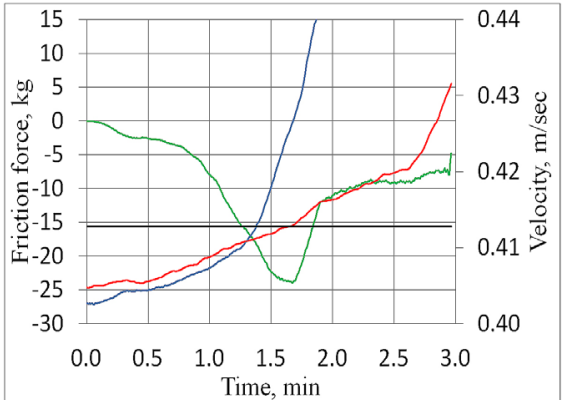

b)

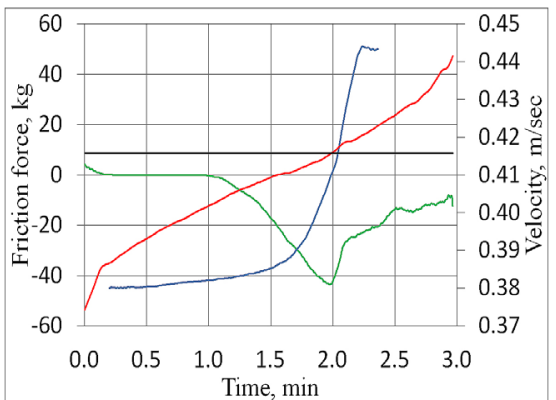

c)

Figure 8: The change in the specimen hoop and axial friction components and the specimen velocity over time in complex rotation and the specimen longitudinal movement for different contact force values: a) 50, b) 100, c) $150 \mathrm{~kg}$. (See online for color version of this figure.)

— axial friction force, - hoop friction force, - specimen hoop velocity - casing hoop velocity.

The friction factor dependence in the circumferential direction $k_{\theta}$ and the friction factor dependence in the axial direction $k_{a}$ on the relative hoop velocity at the contact point $\bar{v}_{r}$ for different values of the contact force are shown in fig. $9 \mathrm{a}-\mathrm{c}$. 


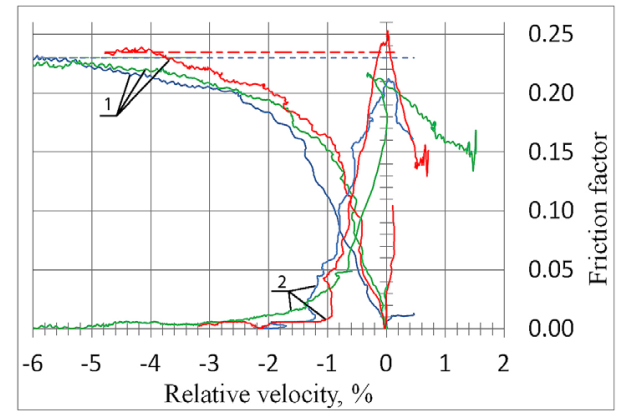

a)

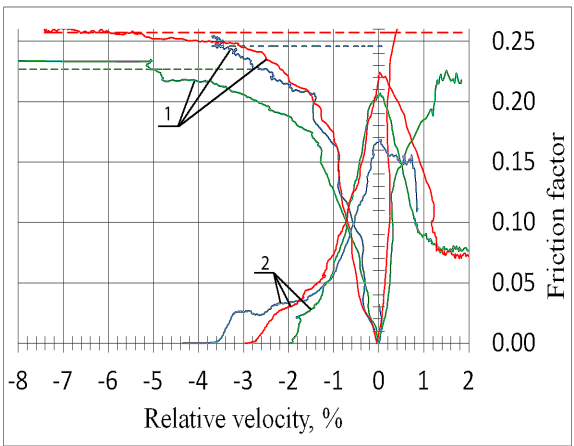

b)

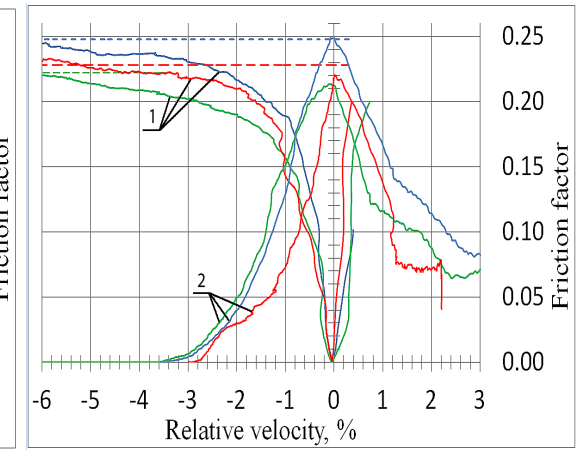

c)

Figure 9: The friction factor dependence in the circumferential direction (1) and the friction factor dependence in the axial direction (2) on the relative hoop velocity at the contact point for different values of the contact force: a) 50 , b) 100 , c) $150 \mathrm{~kg}$.

As it appears from the curves in fig. 9, if the relative velocity at the contact point is equal to zero, then the friction factor in the circumferential direction tends towards zero whereas the friction factor in the axial direction increases to its maximum value, which is equal to «pure» sliding, as if a specimen and a casing were not rotating at all.

\section{Test results analysis. Conclusions}

The experimental study allowed us to find answers to both questions:

1) If a point's relative hoop velocity at the contact point $\left|\bar{v}_{r}\right| \geq 0.04-0.05$ then the friction factor in the circumferential direction $k_{\theta}$ is equal to the sliding friction factor $k_{\theta 0}$ and it practically does not depend on velocity $\bar{v}_{r}$. If $\left|\bar{v}_{r}\right|<$ 0.04-0.05 then friction factor $k_{\theta}$ decreases sharply, reaching almost zero when $\bar{v}_{r}$ $=0$; 
2) When the relative hoop velocity in the contact's point $\left|\bar{v}_{r}\right| \geq 0.04-0.05$ the axial friction factor tends to zero. When $\left|\bar{v}_{r}\right|<0.04-0.05$ the friction factor increases sharply, reaching the value of the sliding friction factor $k_{a 0}$. Thus the effect of the axial friction force reduction due to a drill pipe rotation disappears when relative hoop velocity at the contact becomes small.

Based on this type of the friction factor dependence in the circumferential direction on the relative hoop velocity at the contact point, fig. 7, 9, the best analytical approximation to this dependence is Pade linear-fractional approximation recommended by Zhuravlev [4]. In this case the formula for the hoop sliding friction factor in complex rotation can be given as:

$$
k_{\theta}=k_{\theta 0} \frac{\alpha_{\theta} \bar{v}_{r}}{1+\alpha_{\theta}\left|\bar{v}_{r}\right|},
$$

where $\alpha_{\theta}=$ expansion coefficient of function $k_{\theta}\left(\bar{v}_{r}\right)$ (fig. 7, 9) to Pade's series of the first order.

When the relative hoop velocity values at the contact point $\bar{v}_{r}$ are «relatively» high, coefficient $k_{\theta} \sim k_{\theta 0}$ (compare to eqn. (2)), and when $\bar{v}_{r} \rightarrow 0 k_{\theta}$ $\rightarrow 0$ also.

The following approximation can be used to determine the dependence of the friction factor in the axial direction on the relative hoop velocity in case of a simultaneous complex rotation and a longitudinal displacement of a specimen:

$$
k_{a}=k_{a 0} \frac{v}{\sqrt{\left[v /\left(1+\alpha_{a}\left|\bar{v}_{r}\right|\right)\right]^{2}+v_{r}^{2}}},
$$

where $\alpha_{a}=$ expansion coefficient of function $k_{a}\left(\bar{v}_{r}\right)$ (fig. 9) to Pade's series of the first order.

When the relative velocity $\bar{v}_{r}$ magnitude is high, $k_{a} \sim k_{a 0} v / v_{r}$ (compare to eqn. (3)), and when $\bar{v}_{r}$ is close to zero, $k_{a} \sim k_{a 0}$.

Equations (5) and (6) were obtained based on the experiments conducted under condition that $v_{\varphi}>>v$, which is almost always true for drilling operations. In order to verify these formulas for weakening condition between $v_{\varphi}$ and $v$ additional experiments will have to be conducted to determine a possible friction factor dependence in the circumferential direction $k_{\theta}$ on longitudinal velocity $v$.

It is impossible to measure the rolling friction force that develops in case of a specimen's ideal whirling, $\bar{v}_{r}=0$, using available type of testing equipment because the force is too small. If we want to take rolling friction into account it is logical to suggest using a modified formula for friction factor $k_{\theta}$ :

$$
k_{\theta}=\left(k_{\theta}-\bar{k}_{\theta r}\right) \frac{\alpha_{\theta} \bar{v}_{r}}{1+\alpha_{\theta}\left|\bar{v}_{r}\right|}+\bar{k}_{\theta r} \operatorname{sign} \bar{v}_{r}
$$

where $\bar{k}_{\theta r}=2 k_{\theta r} / d ; k_{\theta r}=$ rolling friction factor. 
It is worth mentioning that there was certain instability in the recordings of the friction force components during the testing. This instability was caused by inaccuracy in measurements due to friction losses in the shaft bearing, surface finish defects and a specimen's surface wear, etc. Nonetheless, main mechanism obtained as a result of this testing allows us to argue that classical Coulomb law needs to be modified based on the proposed formulas for the conditions of combined kinematics.

\section{References}

[1] Dupriest, F.E. and Sowers, S.F., Maintaining steerability while extending gauge length to manage whirl. Presentation at the SPE/IADC Drilling Conf. \& Exhibition, Paper SPE 119625: Amsterdam, 2009.

[2] Heisig, G. and Neubert, M., Lateral drillstring vibrations in extended-reach wells, Presentation at the IADC/SPE Drilling Conf., Paper IADC/SPE 59235: New Orleans, Louisiana, 2000.

[3] Samuel, R., Friction factors: what are they for torque, drag, vibration, bottom hole assembly and transient surge/swab analyses? 2010, Presentation at the IADC/SPE Drilling Conf. \& Exhibition, Paper IADC/SPE 128059: New Orleans, Louisiana, 2010.

[4] Zhuravlev, V.G., The model of dry friction in the problem of the rolling of rigid bodies. Journal of Applied Mathematics and Mechanics, 62(5), pp. 705-710, 1998. 